\title{
On the Fault Line: A Qualitative Exploration of High School Teachers' Involvement with Student Mental Health Issues
}

Kate L. Phillippo

Loyola University Chicago, kphillippo@luc.edu

Michael S. Kelly

Loyola University Chicago, mkell17@luc.edu

Follow this and additional works at: https://ecommons.luc.edu/education_facpubs

Part of the Education Commons

\section{Author Manuscript}

This is a pre-publication author manuscript of the final, published article.

\section{Recommended Citation}

Phillippo, Kate L. and Kelly, Michael S.. On the Fault Line: A Qualitative Exploration of High School Teachers' Involvement with Student Mental Health Issues. School Mental Health, 6, 3: , 2014. Retrieved from Loyola eCommons, Education: School of Education Faculty Publications and Other Works, http://dx.doi.org/10.1007/s12310-013-9113-5

This Article is brought to you for free and open access by the Faculty Publications and Other Works by Department at Loyola eCommons. It has been accepted for inclusion in Education: School of Education Faculty Publications and Other Works by an authorized administrator of Loyola eCommons. For more information, please contact ecommons@luc.edu.

\section{c) (i) $\odot$}

This work is licensed under a Creative Commons Attribution-Noncommercial-No Derivative Works 3.0 License. (c) 2014 Springer Science + Business Publishing New York. 


\section{On the Fault Line: \\ A Qualitative Exploration of High School Teachers' Involvement with Student Mental Health Issues}

Reformers and mental health advocates have long characterized K-12 schools as ideal locations for providing mental health services, particularly for students who might not otherwise have access to these services (Atkins et al., 2010; Dryfoos, Quinn \& Barkin, 2005). Belief in schools' capacity to respond to students' emotional and behavioral needs is further evident in federal initiatives that support Response to Intervention (RTI) and state-level promotion of primary prevention efforts embedded in a Positive Behavior Supports (PBS) framework (Sugai $\&$ Horner, 2009). Alongside these initiatives, school-based mental health practitioners ${ }^{1}$ (SBMHPs) argue that they are positioned to provide the continuum of services and supports that can complement American schools' increased focus on student academic outcomes (Frey, Lingo, \& Nelson, 2008; Kelly \& Lueck, 2011). However, an essential variable in effective school-based mental health $(\mathrm{SBMH})$ services - the crucial role that teachers play in their relationships with students and in their student-centered work with SBMHPs—is often underestimated and minimized. Researchers have noted the central role that teachers play in providing informal mental health support and referrals to SBMHPs, but they also note how infrequently teachers are fully integrated into SBMH work (Burke \& Paternite, 2007; Weist et al., 2001).

Research on student-teacher relationships underscores teachers' contributions to student well-being and achievement. Positive student-teacher relationships—as indicated by teacher behaviors such as the demonstration of personal interest in individual students and a willingness to provide help beyond instructional assistance—are associated with elevated student achievement and engagement (e.g., Lewis et al., 2012; Roorda et al., 2011) and reduced levels of

\footnotetext{
${ }^{1}$ We refer to professionals including school counselors, school social workers, school psychologists, and community mental health providers who work in school settings as school-based mental health professionals or SBMHPs.
} 
dropout and health risk behaviors (e.g., Croninger \& Lee, 2001; McNeely \& Falci, 2004). Additionally, students with mental health and behavioral concerns such as depression and aggressive behavior were found to have improved academic, social and psychological outcomes when they experienced teacher support (e.g., Meehan et al., 2003; Reddy et al., 2003).

Current initiatives in K-12 education attempt to capitalize on teachers' potential contributions to student well-being, intentionally placing teachers in positions that require them to provide various forms of psychosocial support that at times look like informal mental health support. The KIPP charter school model, for example, is well known for its expectations that teachers do whatever is necessary-including home visits, arranging mental health and social services, responding to after-hours student phone calls and providing informal counseling—to promote students' academic success (Mathews, 2009). Advisory programs in secondary schools also place teachers in a position where they informally counsel student advisees as part of broader student support responsibilities (Galassi, Gulledge \& Cox, 1998; McClure, Yonezawa \& Jones, 2010). The small schools movement, which grew during the late 1990s and led to the opening of high schools that currently enroll thousands of American students, also stresses the importance of teachers providing personalized support to students through individualized instruction and long-term student-teacher relationships (Strike, 2010). The late Theodore Sizer, a leading small schools proponent, asserted that "good teachers are good counselors. .. students turn to them for help, whether or not their titles identify them as 'guidance' people" (Sizer, 1992; p. 137). These responsibilities diverge from teachers' traditional, class-based instruction responsibilities (Darling-Hammond, 1997; Lortie, 2002), which have been reinforced by schools' organization into differentiated, specialized positions (Tyack, 1974) and limited guidance or training for teachers about students' psychosocial needs (Koller \& Bertel, 2006; Phillippo, 2013). 
Opinions vary, however, about how and whether teachers ought to be involved with student mental health issues. Franklin and colleagues' recent meta-analysis of school-based social-emotional and behavioral interventions indicates that teachers (in $41 \%$ of the included studies) served as primary or co-interventionists in classroom-based efforts to address a range of student emotional and behavioral issues (Franklin, Kim, Ryan, Kelly, \& Montgomery, 2012). Other studies indicate that well-trained teachers deliver formal mental health interventions (Jaycox et al., 2009) and daily behavioral interventions (Owens et al., 2012). When scholars acknowledge the importance and effectiveness of teachers assuming these responsibilities, however, they tend to downplay teachers' counseling of students (e.g., Reinke et al., 2011), and at times convey a wariness about such activities unless teachers receive extensive training in issues such as trauma, depression and suicide (Freedenthal \& Breslin, 2010; Langley et al., 2010). Other studies describe teachers' involvement in SBMH as limited to providing service referrals (Atkins et al., 2006; Kelly, 2008). Further, many SBMHPs report providing most of their services to individuals and groups of students in their office outside of the classroom, (Burnham \& Jackson, 2000; Farrell, 2010; Kelly et al., 2010a; Kelly \& Lueck, 2011). Together, these findings create an image of the teacher's limited role related to student mental health support, even though evidence suggests that teachers could contribute more fully in this area

The expanded school mental health (ESMH) model acknowledges differences between teachers and SBMHPs, but recognizes the need for a shared agenda where teachers and SBMHPs collaborate to provide a "full continuum of mental health promotion programs and services in schools" (Weist \& Murray, 2007, p. 3). This model frames our exploration of teachers' and SBMHPs' perceptions of their work together. Although proponents of the ESMH model do not advocate that teachers assume the sole and primary role of providing formal mental health 
support to students, they depict teachers as providing more general, informal psychosocial support, in which their interpersonal relationships with students support students' coping with issues such as community violence, family disruption and depression. In this way, teachers' efforts to provide support lead to their involvement with their students' mental health issues. Additionally, proponents of the ESMH model argue that student well-being and overall learning outcomes improve when a range of opportunities for mental health treatment and promotion (which we understand to include formal and informal supports) are offered by all the adults in the school setting (Schoolmentalhealth.org, 2009; Weist \& Murray, 2007).

As scholars and practitioners explore how teachers might contribute to student mental health, a virtual fault line exists where divergent understandings of and approaches to student support meet. Like geological fault lines, where tectonic plates meet and shift against one another, the ground is unstable but exceptionally fertile. Uncertainty about teachers' and SBMHPs' respective roles, responsibilities and best practices exists, and so does the potential to expand and enhance the range of supports available to students. This article explores this "fault line." We analyze the nature of teachers' involvement with student mental health issues and their provision of informal mental health support, exploring these phenomena in small high schools that use advisory programs and also employ SBMHPs. While the small high school is a unique organizational setting that markedly differs from more conventionally-organized schools, it provides an important view of what happens when all teachers, not just those who gravitate towards student mental health issues, engage more substantively with student mental health. Using qualitative data collected at three school sites, we explore how teachers responded to expectations that they provide informal mental health to students, how this work intersected with the work of SBMHPs, and how organizational conditions impacted the work of both groups of 
professionals. With this research, we strive to help SBMHPs identify opportunities to engage teachers in student mental health promotion. We also hope to illustrate the challenges that emerge from such work. Additional knowledge about teachers' engagement with student mental health can inform not only intervention research involving teachers, but also SBMHP training programs that prepare professionals to work alongside teachers in K-12 settings.

\section{Research Questions}

Since teachers have had limited involvement with student mental health issues, and since teachers and SBMHPs have largely worked in isolation from one another, we hoped to learn more about what happens to both groups' work when teachers step into the realm of student mental health. In particular, we were interested in understanding what teachers actually do in such situations, what kinds of interactions occur between teachers and SBMHPs related to teachers' informal mental health support responsibilities, and how these phenomena might vary according to organizational conditions. We therefore posed the following research questions:

1. In schools where the teacher role is defined to include informal student mental health support, how do teachers respond?

2. Under these conditions, how does SBMHPs' work intersect with teachers' work?

3. In what ways do organizational conditions, such as the amount of SBMHP services and the extent of teachers' mental health support responsibilities, impact teacher and SBMHP practice related to student mental health?

\section{Method}

\section{Study Design and Setting}

This study draws data from a larger project that investigated teachers' student support roles in small high schools (Phillippo, $2010 \&$ 2013). The present study's specific research 
questions called for an exploratory, comparative case study, which is compatible with the larger project's design and selection criteria. Yin (2009) described the case study as a way to investigate social phenomena and generate explanations about individuals' responses to them, an approach well-suited to research about how teachers address student mental health needs. The exploratory case study approach adapts the case study method to topics—such as this study'sfor which the existing research base is limited, rendering hypothesis testing not yet feasible (Streb, 2010). Further, the use of multiple sites for the sake of comparing the impact of organizational conditions (research question 3) is consistent with Yin's (2009) emphasis on multi-site study replication as a means for analyzing the variation of key variables.

Purposeful site selection criteria for the larger study led to the inclusion of schools where teachers encountered varying degrees of expectations about, and varying levels of support for, their work providing informal mental health support to students through their work as advisors. Selection criteria sought schools a) that had active advisory programs staffed by generalist teachers, b) whose leadership formally and informally communicated expectations to teachers that they know their advisees well and intervene in situations that threatened their academic progress or personal well being, and c) that employed SBMHPs. Relevant to research question 3, the first author also sought sites that varied in degree on criteria $\mathrm{b}$ and $\mathrm{c}$.

The sites selected were three small high schools in a large metropolitan area of California. From a possible sample of over twenty small high schools in the geographic area, the first author initially approached the seven schools whose websites indicated that they had on-campus mental health services as well as advisory programs staffed by teachers. Two of these schools' principals declined to participate, one school did not fit the study criteria upon further exploration (having discontinued mental health services), and one school planned a radical 
overhaul of its mental health services for the data collection year, which suggested the potential presence of confounding variables. This left three schools that met inclusion criteria and provided sufficient contrast with one another according to the study's design.

\section{Participants}

The sites selected—King, Los Robles and Western ${ }^{2}$ — were small high schools enrolling less than 400 students (see Table 1). These schools also had substantial proportions of students of color and students from lower-income families. Each school required full-time classroom teachers to serve as advisors in student advisory programs. The advisory programs all involved an advisory class, although the programs' foci and the instructional time dedicated to them varied (as illustrated in table 1). At all three sites, teachers and advisees met multiple times each week, over two to four school years, and teachers in the advisor role were expected to identify and, to varying degrees, address advisee problems that came to their attention. King placed much lower psychosocial support expectations on teachers serving as advisors, since its advisory program focused more on academic support. In contrast to Los Robles and Western, where teachers were expected to personally follow up on student psychosocial matters such as personal crises and behavioral issues, King's leadership explicitly told teachers to refer such matters to SBMHPs. This site-to-site difference with regard to informal mental health support expectations of teachers provides for a useful comparison, given that personalized treatment of all students (but not informal mental health support) was expected of all teachers across the three schools.

Each school engaged at least one SBMHP (amount of SBMHP services, SBMHP pseudonym and area of certification are listed in table). The level of SBMHP presence varied across the three sites, from limited (one part-time SBMHP intern at Western) to extensive (a student health center with mental health services at King, multiple providers at Los Robles).

\footnotetext{
${ }^{2}$ All names of schools and individuals at these schools are pseudonyms, assigned to protect participants' privacy.
} 
Data were collected during the 2007-2008 school year at all three sites, with data collection beginning during the 2006-2007 school year at Los Robles only, and then following a staggered schedule with Los Robles followed by Western and King.

[Insert table 1 here]

\section{Measures and Data Collection Procedures}

This study incorporated observational and interview data, which provided multiple sources of information (Emerson, Fretz \& Shaw, 1995; Merriam, 2009) about schools' and educators' approaches to informal mental health support.

Observation measures and procedures. Over the course of six weeks, the first author adapted ethnographic methods (e.g., Spindler \& Spindler, 1987) and observed all content-area and advisory classrooms at each site (94 in total), staff meetings and unstructured periods (e.g., passing periods and lunch recess) for approximately 20 hours per week, taking field notes focused upon the nature of student-teacher interactions, the scope of teacher responsibilities, and activities that took place during advisory classes. During this period, the first author also engaged in brief, informal conversations, recorded in field notes, with teachers and SBMHPs whom she observed or encountered at the school sites. With these conversations, the first author sought to clarify what she had observed, specifically regarding the observations' foci. Field notes were reviewed to identify general themes that in turn informed the development of semi-structured interview protocols.

Interview measures and procedures. Semi-structured interviews with both teachers and SBMHPs this study's second stage of data collection. Teachers who agreed to participate in interviews ( $N=46$ of a possible 50 ) answered questions about different student mental health issues that they encountered, how they responded, the ways in which they worked with SBMHPs, 
and their impressions of and wishes for SBMHP work in their schools. SBMHP interviews ( $N=7$ of a possible 8) similarly focused on student mental health issues, approaches to serving students, SBMHP work with teachers, and SBMHP impressions of teachers' work in the realm of student support (sample questions follow in appendix A). Both sets of interviews took place over two 3045 minute sessions, allowing for follow-up questions and further development of rapport between the researcher and participants.

\section{Data Analysis Procedures}

Analysis began during the data collection process, and combined the strategies of reviewing field notes, discussing preliminary findings with participants, exploratory readings of interview transcripts and analytic memo-writing, all in the interest of building and testing explanations about the data (Taylor \& Bogdan, 1998; Yin, 2009). During this first stage, the first author developed a list of possible codes for interview transcript analysis while conducting and preliminarily analyzing interview data. Multiple readings of interview transcripts and written interview summaries informed further development of the code list. This process combined methods characteristic of a "tight, prestructured qualitative design"' (Miles, Huberman \& Saldaña, 2013, p. 19), blending concepts from this study's literature review (e.g., the parameters of teacher roles) with a more open-ended search for themes (such as organizational constraints upon teacher-SBMHP collaboration) that emerged from the data (Merriam, 2009). Individual codes fell into broader categories that included role definition (by professionals and by school), structures and resources related to teachers' informal mental health support responsibilities, teacher responses, and SBMHP involvement with teacher(s) (as described in table 2).

[Insert table 2 here] 
During this second stage of analysis, the full set of codes was applied to transcripts using qualtitative data analysis software, followed by the use of case display strategies (Miles et al., 2013) to focus the interpretation of data via cross-case comparison (across schools and across groups of teachers). While the second author was not involved in the data collection or initial analysis processes (one of this study's limitations), his SBMH intervention expertise complemented the first author's expertise in organization-level study of SBMH practice. The second author engaged with the data in the third stage of analysis to strengthen the reliability of interpretive processes. This stage involved the second author's full review of transcripts and codes, a decision to maintain existing codes, and subsequent discussion, development, and application of new codes, leading to an additional round of data interpretation and explanationbuilding. The authors established code reliability by comparing application of the same codes, adjusting the codes' definitions until they agreed upon code definition and application, and then applying codes to the transcripts (Kvale \& Brinkmann, 2009; Saldaña, 2013).

\section{Results}

In keeping with our first research question ("In schools where the teacher role is defined to include informal student mental health support, how do teachers respond?"), our data reflect that teachers' work was shaped by the more explicit inclusion of informal student mental health support responsibilities. Only $7 \%$ of participating teachers reported that they had ever held jobs where they served as advisors, representing new responsibilities for most. Teachers at all three schools regularly encountered student mental health issues, even at King, the school with the most modest expectations of teachers regarding student support. However, teachers' responses to role expectations only sometimes included substantive engagement with student mental health issues, due to different ways in which they defined the their role. Our second research question 
(“Under these conditions, how does SBMHPs' work intersect with teachers' work?') led to findings that, even though many teachers willingly engaged with students around mental health issues, with SBMHPs often supporting these efforts, SBMHPs' and teachers' work with shared students at times did not overlap. This arrangement seemed influenced by organizational constraints that reflected a failure—at all three schools, and regardless of expectations of teachers or the extent of SBMHP services—-to bring school structures or practices in line with teachers' informal mental health support responsibilities. These organizational conditions' impact on practice (related to research question 3: "How do organizational conditions, such as the amount of SBMHP services and the extent of teachers' mental health support responsibilities, impact teacher and SBMHP practice related to student mental health?") was consistent across participating schools, contributing to tensions around issues of SBMHP accessibility, the delineation of professional responsibilities and the confidentiality of student information.

\section{Teachers Consistently Encountered Student Mental Health Issues}

At all three schools, teachers regularly encountered substantial mental health-relevant issues through their work as content-area teachers and as advisors. These encounters occurred regardless of the degree to which the schools required teachers to provide informal mental health support through their work as student advisors. Teachers spoke of students experiencing issues such as unplanned pregnancy, family disruption due to family members' incarceration and immigration issues, community violence (multiple incidents of students losing friends and family members to gang violence), homelessness, depression and drug abuse. We identified three types of encounters: those related to teachers having assigned responsibility to manage advisee behavior, student disclosure to teachers, and teachers' coordination of support for students.

[Insert Table 3 here.] 
Los Robles and Western assigned teachers, through their advisor role, the responsibility to address student behavior. These responsibilities were, in many ways, most pronounced at Los Robles, where teachers who served as advisors were required to receive (in their own classrooms) students sent out of class due to misbehavior (rather than to an administrator's office). Teachers were expected to debrief these incidents with their advisees and to determine what (such as apology letters, phone calls to parents, or detention) should occur as a result. Similarly, Los Robles' teachers were required to implement behavior plans for their advisees (using a system that required daily reports from all of an advisee's teachers). Accordingly, teachers received rich information about within- and beyond-school factors associated with advisee misbehavior. Western's administration similarly required advisors to oversee behavior plans and, while not as uniform as Los Robles, to take in students sent out of another class.

Students also disclosed information about their own personal and mental health issues in conversations with their teachers. This happened at all three schools including King, the school that limited teachers' advisor role to academic guidance, as the examples in this paragraph indicate. Mr. Colvin's experience, after he asked a first-period student why she had her head down on her desk, illustrates this point. She responded that she'd gone to bed at 3 the night before after being at the emergency room with a friend who had been shot in the head. Sometimes students disclosed urgent situations to their teachers, seeking help. One of Mr. Chavez's students told him that she had ingested sleeping pills, and then disclosed that she had been molested numerous times by an adult family member, which led him to contact protective services and emergency services to address her student's immediate needs. Still other students discussed their concerns and difficulties over time with teachers. Three teachers at King spoke of a transgendered student who sought them out to discuss school and personal situations related 
to her gender identity and presentation. While teachers at all three schools referred students for formal mental health support services, their engagement with student mental health issues continued, even at King where this was required of neither advisors nor content-area teachers.

Teachers also encountered student mental health issues due to their substantial responsibility for the coordination of support and service referrals, particularly at Los Robles and Western, schools that formally designated advisors as students' lead teachers. "Your role as an advisor is to follow up on your students' needs and issues," Ms. Little (Los Robles) explained, reflecting expectations at both schools that were conveyed explicitly by school leadership and via faculty norms. Teachers at Los Robles and Western coordinated parent-teacher conferences, addressed emergent academic problems and also communicated and coordinated with SBMHPs, as well as with their student advisees' outside service providers (such as child protective services, probation officers, therapists, psychiatrists, shelter workers and foster care workers). Los Robles provided information to teachers on how to contact different community agencies to arrange services for their students, although teachers often found this information outdated.

Through the activities described above, teachers encountered the psychosocial aspects of their students' lives, sometimes in unpredictable or even startling ways. They not only learned about students' mental health issues, but often addressed them in conversation and in their actions. Interestingly, this work occurred at King, which defined its advisory program as academic in nature, as well as at Los Robles and Western, which more formally required teachers to provide informal mental health support to students through their work as advisors. Teachers, all working at schools with small faculties, had layered opportunities to interact with students. They taught multiple courses, carried advisory classes, led extracurricular activities, and provided hallway and yard supervision. Through these interactions, all participating teachers 
knew of (and described) their students' struggles with challenging psychosocial circumstances. How teachers engaged with students around these matters, however, did vary among teachers.

\section{Divergent Teacher Interpretations of Their Role Regarding Student Mental Health}

While teachers' exposure to student mental health issues was consistent across the three schools, their responses to student mental health issues ranged between two poles: a diffuse definition of their role, in which they engaged with student issues to the extent of their abilities, or a narrower role definition, in which teachers excluded mental health issues from their day-today work (as illustrated in table 4). Overall, the split between these two types of role definition was nearly even, with $48 \%$ of teachers enacting a more diffuse role and $52 \%$ claiming a narrower role. In keeping with expectations placed on them as advisors, a number of teachers at Los Robles and Western (roughly half at each school) took on a diffuse role in which they engaged with their students' mental health issues, providing psychosocial support where they could. King did not formally assign these responsibilities to advisors, but some teachers (about one-third, notably lower than the proportion at Los Robles and Western) assumed them anyway. While

[Insert table 4 here.]

some teachers consistently held to either a diffuse or narrow role definition, others vacillated between the two due to student needs, collegial or administrator pressure to serve students (particularly at Los Robles and Western), or the topic at hand. For example, some teachers reported that they did not discuss topics such as sexuality or gang involvement with their students due to their sense of limited expertise with such issues.

Teachers at all three schools reported engaging with students and their various service providers around issues such as family disruption, death, community violence, sexual assault, pregnancy, homelessness, and incarceration. While Los Robles and Western assigned these 
responsibilities via the advisor role, some teachers at King took these responsibilities on voluntarily. Mr. Hart (Los Robles), a second-year teacher, reported weekly contact with an advisee's foster care worker to address issues related to her mental health, school performance, and transportation to and from school from her group home. Even though she did not have advisory responsibilities for Andréa, Ms. Williams (King) had learned about Andréa's family (that her mother had suddenly left the family) and stepped in when she began showing unusually negative affect and began dating a student who was involved with a gang (another of Ms. Williams' students). "I knew. . . that history so I talked to her a lot and I would pull her in and say what is going on, do you know you're dating a gang member, what do you think about that?" When Andréa's advisor reported a suspected abuse situation in Andréa's home to the authorities, that advisor asked Ms. Williams to speak with Andréa. The school's designation of the advisor role did not determine who ultimately intervened, but rather Ms. Williams' own definition of her role. When the first author asked her why she had taken on responsibilities not assigned by her principal, she replied, "How can you not deal with these things?"

Diffuse-role teachers engaged with students' mental health issues in a number of ways. Many teachers discussed and attempted to informally address student needs. Ms. Renato (Western),learned about her advisee Vanessa's depression and mother's long-term absence from the U.S. through a series of individual conversations to follow up on Vanessa's frequent absences. At other times, teachers found themselves as first responders to student problems or crises. Ms. Curran (Los Robles) found herself taking the lead on Los Robles' response to her suicidal advisee: "She (the psychologist) couldn't be here to see him but she walked me through the steps of how to deal with him and then to get him to go talk to other people." Ms. Curran described this experience, in which she was responsible for drawing up a no-harm contract with 
her student, as "twisted," and like being "thrown into the water, and you're scrambling." This example illustrates how teachers at times had to address situations for which they felt unprepared, even when they accepted the responsibility (as Ms. Curran did), or even embraced it.

Other teachers avoided direct engagement with their advisees or content-area students' mental health issues, choosing a narrower role limited to academic instruction. "I try not to get too involved," Ms. Carbonell, one of King's founding teachers, told me about psychosocial issues and subsequent intervention. "I don't feel prepped or inspired to do it. I don't have solutions for them on that. I have solutions for them around graduating and doing well on tests. I do not want to get involved in a kid's life," she insisted. Other teachers echoed these sentiments, saying that they felt emotionally overwhelmed by students' issues, did not agree with assigning informal mental health support responsibilities to teachers, felt unwilling to compromise their status as academic instructor, or felt that they lacked the necessary skills to intervene. Narrow-role teachers stated a preference that SBMHPs, rather than teachers, address student mental health issues. At Los Robles and King, schools that employed multiple SBMHPs, teachers who preferred a narrow role referred students for services and considered their responsibilities complete. At Western, however, where one half-time SBMHP provided mental health services, narrow-role teachers faced a choice between using sparse SBMH services, doing work they did not want to do, or doing nothing. All teachers, regardless of the degree to which they incorporated mental health support into their work with students, saw their work as distinct from SBMHPs' work. We next explore how these two groups of professionals' work intersected. School-Based Mental Health Professionals' Work According to Teachers: Led (But not Dominated) by Individual Counseling for Students 
Teachers elaborated four forms of SBMH services that related to their work in the realm of student mental health (illustrated in Figure 1). Participating teacher reported a range of SBMHP actions - those of individual counseling for students, consultation with teachers, resource brokerage and teacher professional development - that connected to their involvement with student mental health issues. Consistent with research suggesting that SBMHPs continue to emphasize office-based counseling in their work (e.g., Burnham \& Jackson, 2000; Farrell, 2010; Kelly \& Lueck, 2011), teachers most frequently mentioned individual counseling as the service SBMHPs provided that supported their work with student mental health issues. However, teachers also referred to other SBMHP work that also intersected with their own efforts. At Western, a school that did not have consistent SBMHP presence until midway through the year in which data was collected, far fewer teachers interacted with SBMHPs and fewer kinds of teacher-SBMHP interactions occurred. Different forms of SBMHP work (as reported by teachers) illustrate actual and possible points where SBMHPs can integrate their work with teachers' work. However, SBMHP services that seemed most compatible with teachers' support responsibilities often proved the most elusive, given how schools structured those services.

[Insert Figure 1 here.]

Individual counseling. Thirty-six of 46 teachers — across all three schools_-reported that their work with SBMHPs involved referring students to SBMHPs and those SBMHPs then providing individual counseling. Teachers understandably looked to SBMHPs for more formal clinical mental health services for their students, and no wonder: they consistently expressed appreciation for the expertise that SBMHPs possessed, and for their ability to address student needs outside of the confines of the classroom. "I don't think I am trained or capable of giving a student advice regarding family issues or things that they are really, really struggling with 
emotionally," explained Ms. Powers, who expressed confidence in Los Robles' SBMHPs to do this work.

The preponderance of this type of teacher-reported SBMHP service reflects not only SBMHPs' skills and at times teacher role definition that excluded any kind of mental health intervention, but also organizational and professional decisions that privileged individual counseling. All SBMHPs in this study reported that they spent the bulk of their time providing individual, office-based services and were very rarely included in staff meetings, professional development days or leadership teams, even though they would have liked to have been. Additionally, 5 of 8 SBMHPs were employed contractually by schools, relying on billable hours to support their positions, which contributed to an emphasis on clinical services. Further reinforcing the image of SBMHPs working separately from other professionals in their schools, some SBMHPs described themselves as mental health providers located inside of schools. Dr. Beltrán, who led King's school-based clinic, described his job in this spirit:

This is basically an independent community clinic that just happens to be on a school campus. We really try to stress that when a student crosses that threshold, from the front door, that things are calm, systematic, predictable, which helps separate [from the school]. Teachers also saw formal mental health services as something apart from the school's main activities. Mr. Carmichael, a teacher who spoke very highly of all of King's SBMHPs, described the student health clinic SBMHPs as "more like your doctor, your psychiatrist," compared to Ms. Ortiz, King's counselor. Ms. Ortiz herself described the difference between her work and the student health clinic's when stating, "The clinic rarely leaves the office." Likewise, teachers at Western saw Ms. Cruz as an individual counselor of students to the extent that they rarely interacted with her for other reasons. Mental health services of this variety took place almost 
entirely apart from teachers' work with students, with teachers involved primarily for the purpose of providing referrals and releasing students from class to meet with SBMHPs.

Teacher Consultation. Teachers at all three sites (28 of 46) described a consultative use of SBMHPs' services, defined by Albers and Kratochwill (2006) as "an indirect service delivery model in which a consultant works with a consultee with the desired outcome being a change in the client's behavior" (p. 971). School-based consultation is a flexible practice that can take on various forms such as student-centered consultation, teacher coaching or more systemicallyoriented organizational consultation, and can range from informal and spontaneous to highly structured (such as regularly scheduled, team-based consultation) (Meyers, Meyers, Graybill \& Proctor, 2012; Sabatino, 2009). Additionally, every participating SBMHP reported updating teachers about whether students they had referred were receiving services or not (although five participants reported instances in which they never found out whether students they referred had connected with a SBMHP). Beyond this cursory, time-limited exchange of information, however, we found modest evidence of more comprehensive interactions, in which SBMHPs and teachers consulted with each other more substantially and for a wider range of purposes. Six of 46 teachers (5 at Los Robles, 1 at King) reported more comprehensive consultation with SBMHPs.

SBMHPs consulted with teachers in diverse ways. Some SBMHPs turned service referrals into consultation opportunities. Ms. Williams (King), who was highly involved with both advisees and content-area students, recounted a consultation, which she described as helpful, with King's student clinic staff following a student's panic attack. 
I saw her (the student) out in the courtyard just crying and having trouble breathing so I walked her to the clinic and then the woman at the clinic actually said "She wants to go back to your class, is that okay, let me tell you a little bit about what is going on." Teachers and SBMHPs also reported working together to brainstorm responses to student difficulties or support needs, with each person contributing knowledge of the student as well as relevant skills and ideas to the consultation. Additionally, SBMHPs consulted with teachers to help them strategize about and think through their own work with students. Teachers also consulted with SBMPHs for the purposes of getting guidance about their own crisis intervention responsibilities (e.g., whether they needed make a report of suspected child abuse), exchanging background information on students, and updating one another on shared students. Ms. Gillespie (Los Robles) worked with Ms. Peterson, a social worker, to get guidance on how to handle frequent crisis phone calls from her advisee Omayra.

I called Ms. Peterson and I am like, I am stressed out, I don't know how to support Omayra, I am not trained to do this, I feel like her life is in my hands right now and I am really scared. And so then Ms. Peterson becomes my counselor. She said, "This is not your position, not your job.” So Ms. Peterson really saved me.

These examples illustrate how teachers and SBMHPs have a broad range of consultation opportunities, far beyond brief check-ins about service referrals and updates. However, consultation required both teachers and SBMHPs to circumvent conventional arrangements. Teacher-SBMHP consultations often took place outside of school hours, during evening phone calls or email exchanges, since teachers and SBMHPs had difficulty connecting during the school day, with teachers following a bell schedule and SBMHPs' work focused on individual 
counseling. With the exception of Mr. Ortiz (King's full-time counselor), SBMHPs were present part-time at their school sites, rendering it even more difficult to connect with teachers.

Brokerage of community resources. Seven of 46 teachers reported that when they found themselves in the position of referring students to out-of-school providers for mental health and social services, they turned to SBMHPs. All seven worked at either King or Los Robles, where more SBMH services were available (compared to Western). These teachers appreciated SBMHPs' knowledge of services that could benefit their students, even if they themselves did not ultimately provide the services. "I don't have the connections," Ms. Gutierrez (King) explained, "the resources, the places to refer them to. Ms. Ortiz (counselor) has all that information under her belt." Most of the SBMHPs in this study were employed by community organizations, and easily helped teachers connect students to these organizations' services, such as health care, legal representation and financial assistance.

Teacher professional development. The fourth SBMHP role described by teachers, that of teacher professional development provider, concerned SBMHPs' work more explicitly teaching educators. Only 6 of 46 teachers (all at Los Robles) reported such work by SBMHPs. SBMHPs' work teaching educators at times seemed like an extension of student-centered consultation. Ms. Little (Los Robles) described such a situation, when she witnessed an SBMHP providing just such guidance to Mr. Orff, a teaching colleague who was "in a difficult situation with a parent at the front of the building. She was quietly observing from the sidelines, and then when the parent left she was coaching Mr. Orff on how best to handle parents like that." This resembles what Borko (2004) calls situated teacher professional development, in which individuals possessing expertise share it with teachers in need of support and skills to address pressing student needs. Dr. Moisés (Los Robles) also provided more formal, didactic teacher 
professional development, and this occurred only once (during the year prior to data collection) when she led a session on identifying and responding to adolescent crises. Hungry for skills they could use when advising their students, Los Robles' teachers spoke glowingly of this one session, which they consistently called "professional development." Ms. Mitchell said, Dr. Moisés “came in and talked to us about what appropriate crisis response looks like. And not enabling, learning how to not enable."

SBMHPs responded with surprise when asked whether they conducted professional development at their schools. Western's administration turned down Ms. Cruz's multiple requests to secure faculty meeting time for mental health-related professional development, citing insufficient time. Only Dr. Moisés (Los Robles) conducted this type of professional development, and while she expressed a wish to do more work like this, it was extremely rare at Los Robles and nonexistent at this study's other sites (no teachers mentioned SBMHPs providing professional development at either King or Western), even though SBMHPs and teachers at all three schools expressed an interest in helping teachers learn more about topics such as abuse and neglect reporting. SBMHPs' time tended to involve individual counseling and individual teacher consultation at all three schools, with little room created by either school administration (or, at times, SBMHPs themselves) for activities such as whole-staff professional development.

\section{Where Teaching Meets School-Based Mental Health: Connections and Tensions}

At all three sites, SBMHPs' work clearly touched upon, and often supported, the work of teachers who were engaged with their students' and advisees' mental health issues. At times, these professionals connected easily and productively, while at other times tensions arose from their interactions with one another. Connections came readily when SBMHPs and teachers could enhance one another's work with shared students. SBMHPs helped teachers by doing things that 
teachers did not typically do, such as taking the lead in a student crisis situation. Teachers generally perceived SBMHPs as helping them address the student issues they (teachers) encountered as they attempted to know their students well, particularly when mental health matters arose. SBMHPs often stepped in with combinations of direct student support and support for teachers themselves. Ms. Goodman (Los Robles) described such a situation:

I had a really tough advisee who was raped. I happened to write her (name) on the board for a conference with me. Then that came out. She had never told any one. I didn't know what to do! So I talked to Ms. Peterson, our social worker.

Ms. Goodman, however, did not want to simply hand off her student, whom she had advised for years, to an SBMHP. She asked for, and got, guidance about how to provide ongoing support to her as an advisor and teacher.

Perceptions of helpfulness went the other way, also: SBMHPs saw teachers as providing essential information on students' well-being, peer relationships and academic performance, as well as insights on student strengths and needs. In this aspect, teachers and SBMHPs seemed to connect easily around complementary skills and perspectives that made it possible to extend each other's ability to serve students. Alongside these connections, which seemed natural in the small school environment where student support was considered everyone's job, tensions arose which made these connections seem at times like they rested on fault lines. We contend that the organizational and professional issues that we have highlighted above—such as organizational structures that separate rather than integrate teachers and SBMHPs and professional norms that promote individual counseling as the primary form of SBMH services-exacerbate the sense of a fault line between teachers and SBMHPs by contributing to tensions around their work with 
shared students. Issues regarding teachers' access to SBMHPs, the delineation of responsibility for students, and confidentiality of student information emerged as areas of informative tension.

Access to SBMHPs. Teachers' access to SBMHPs was important, given their involvement in student psychosocial issues. A number of pragmatic, organizational obstacles interfered with this critical access. SBMHPs reported that they spent a significant portion of their time in their offices seeing individual students, and had minimal or no involvement in faculty meetings, where they might have connected with teachers. One exception involved Ms. Cruz's participation in one of Western's three teacher teams' weekly meetings, which both teachers and Ms. Cruz described as supportive of teacher-SBMHP collaboration. Another exception involved King's counselor holding an optional lunchtime meeting once a month to discuss advisory class issues. SBMHPs' part-time hours (as was the case with all but one participating SBMHP) further limited opportunities for SBMHP-teacher access.

Other difficulties with teachers' access to SBMHPs reflected a lack of clarity about school mental health service processes. The separation of SBMHPs work from teachers' work was particularly pronounced when it came to communication after teachers made SBMH referrals. Teachers at all three schools voiced confusion or frustration about what happened after they made service referrals or when they (or their students) might access SBMHPs. They also reported receiving limited information about whether a written referral had been received, whether students had engaged in SBMH services, and how or when to contact SBMHPs.. While no teacher would find such a situation appealing, it seemed particularly difficult at schools that deliberately put teachers into contact with student mental health issues. Some teachers circumvented arrangements that provided them with limited information, for example making "live" referrals through face to face or phone contact or seeking out information on referred 
students. Ms. Moreno reported that she frequently spoke by phone with Dr. Moisés (Los Robles' Psychologist) during evening hours about shared students. Other teachers, however, simply bemoaned their difficulties accessing SBMHPs while accepting these difficulties as ordinary.

\section{Delineation of teacher and SBMHP responsibility for student mental health support.}

Teachers also reported confusion about where their jobs left off and SBMHPs' jobs began. Teachers' involvement with student mental health bled into SBMHPs' work due to teachers' often close involvement in students' day-to-day lives. The shared responsibility for student support at times carried a lack of clarity about who held ultimate responsibility for specific students. Ms. Janus (Western) felt uncertain about expectations of her once students began working with SBMHPs. "Do you want us to step back on those (student) issues?" she asked rhetorically, expressing confusion about what teachers should do regarding student advisees who received SBMH services but continued to show difficulties such as depression and truancy. Teachers' voiced an appreciation of SBMHPs' specialized training and the need to preserve confidentiality in student-SBMHP relationships, and consistently expressed a desire to not encroach upon their work. Still, teachers did not always know when they were crossing professional boundaries, since the work of addressing student mental health was so unfamiliar. SBMHPs at Los Robles reported that teachers took on more than they could manage relative to student mental health issues. Conversely, teachers at times failed to act when circumstances seemed to warrant intervention, for example treating drug use at school as a strictly disciplinary issue rather than a sign of possible underlying mental health symptoms.

The lack of clear boundaries between teacher and SBMHP work became problematic when neither the SBMHP or a referring teacher (usually the teacher assigned as the advisor) took the lead on addressing student mental health concerns. For example, Kima, a student at Western 
experiencing depression, family conflict, absenteeism, frequent episodes of in-school intoxication and multiple conflicts with teachers and administrators, reported to the first author that, even though she had an assigned advisor, Ms. Willis, and a contract to work with Ms. Cruz, Western's counselor, she had gone several weeks without speaking to either about her difficulties. Neither Ms. Willis nor Ms. Cruz contradicted this description. Ms. Cruz had a difficult time maintaining an appointment schedule with Kima due to Kima's absences and Ms. Cruz's limited hours onsite. Meanwhile, Ms. Willis deferred to Ms. Cruz as the mental health expert, refraining from engagement with Kima's mental health issues once Kima had established initial contact with Ms. Cruz. Kima found herself ironically unsupported in a school that prided itself upon multifaceted student support. The change in teachers' responsibilities, without an associated clarification of how teachers' and SBMHPs' work related to one another (or structures that brought these two groups of professionals together), ripened conditions for such incidents.

Confidentiality. A third area of tension arising at the interface between teachers and SBMHPs concerned the confidentiality of student information, a topic that other scholars (e.g., Chanmugam, 2009; Evans, Sapia, Lowie \& Glomb, 2002; Raines, 2004) have found to raise dilemmas in school-based mental health. SBMHPs expressed a strong commitment to their professions' requirements to preserve the confidentiality of student information (e.g., about a student's involuntary hospitalization for mental health difficulties). Teachers respected this commitment and often did not want to receive sensitive, confidential information. Ms. Powers (Los Robles) explained, "I don't want to know that. I want to see her (a student) make progress, I want to see her be happy with herself and whatever that takes and whatever issues they are, that's good." 
Given teachers' engagement with student mental health issues, however, teachers often felt a need to learn more from SBMHPs about their work with shared students. Ms. Williams explains this perspective: "Ideally there would be that partnership where it could be like, here is what I think is going on, let me send you the kid and they could say okay here's is what is going on, here are ways to deal." SBMHPs also recognized the complicated nature of confidentiality in school settings that promoted a highly personalized environment. "That's probably the biggest hurdle, the thing I think about the most, what I can and can't share or shouldn't share," Ms. George, a social worker, explained about her work with Los Robles' students and teachers. SBMHPs related to confidentiality guidelines in varying ways. Some SBMHPs provided no information without student and parent written consent. "Technically, I can't even say whether or not a person is a patient of mine or not," explained Dr. Beltrán, King's psychologist. By contrast, Ms. Ortiz, King's counselor, said that she regularly exchanged information with teachers about shared students. "This is the way I look at it: nothing is confidential on this campus. How can you support a student if you don't know anything about them?" she elaborated. Ms. Ortiz based her decision upon the understanding, which she described as sometimes implicit and sometimes explicit, that her colleagues keep sensitive student information to themselves. Further, as Ms. Ortiz shared student information, she also received it, with teachers passing information about students along to her. Other SBMHPs. such as Dr. Moisés (Los Robles), fell between to-the-letter and liberal interpretations of confidentiality guidelines:

Once you're above board with the kids, that what you want to do is help them (by sharing sensitive information), and at the same time where the teachers are aware that this is confidential information, but they're dying to help, it's gone pretty smoothly. I'll tell teachers what I think they need, the minimum information. They won't push for more. 
Dr. Moisés' approach reflects an effort to balance consultative demands and opportunities with students' privacy rights, a demanding act in these three schools.

While one might see (and even question) individual interpretation in these SBMHPs' practice related to confidentiality, it is important to also note substantial differences among professions' confidentiality guidelines. The National Education Association's Code of Ethics, of which no participating teachers were aware, requires that educators "shall not disclose information about students obtained in the course of professional service unless disclosure serves a compelling professional purpose or is required by law" (NEA, 1975). This language allows educators to define "compelling professional purpose." Mental health professions' codes of confidentiality (e.g., NASW, 2008), however, explicitly require client consent (and, in the case of minors, parent consent) prior to practitioners' disclosure of any personal information. Similarly, the American School Counselor Association's code of ethics' statements prohibits the disclosure of student information except in cases of imminent danger to students. At the same time, however, the counselor must show "adherence to appropriate guidelines regarding confidentiality, the distinction between public and private information and staff consultation" (ASCA, 2010, Section C.2.a). This statement leaves indefinite the matter of how confidentiality works between SBMHPs and teachers. Inconsistencies in ethical codes between professions, which we believe reflect conflicting professional norms, made it necessary for SBMHPs, teachers and students to navigate multiple, often confusing parameters for handling sensitive student information. Each school presented some version of this confusion, regardless of its SBMHPs' field of practice, suggesting that this issue is one shared by different SBMH fields.

\section{Discussion}


Taken together, this study's findings suggest that teachers who are responsible for providing informal student mental health support responsibilities will encounter student mental health issues, but may not necessarily address them. SBMHPs acknowledged teachers' expanded responsibilities under these circumstances and at times adapted their work in order to support teachers. However, SBMHPs' work continued to reflect a separation rather than a blending of teachers' and SBMHPs' efforts to support students. These findings lend to the image of a fault line between SBMHPs' and teachers' work. Tension and uncertainty existed at the three sites as to how to make use of potentially fertile ground for cross-disciplinary student support in ways that benefited students, honored student privacy, respected different professionals' areas of expertise and did not overextend teachers. From these findings, we call attention to three key points: First, the lack of organizational or professional change around the change in teachers' informal mental health support responsibilities; second, the continued separation of teachers' and SBMHPs' work that this lack of change reinforced; and third, these findings' relevance beyond the limited sphere of small high schools.

In spite of changes to teachers' responsibilities (and teachers' and SBMHPs' general openness to these changes), little else King, Los Robles or Western changed in ways that might have supported teachers' transformed work. Teachers had very little time apart from classroom time and their already overwhelmed prep periods to address student support needs, while SBMHPs spent the majority of their time counseling individual students. School meeting structures very rarely provided for teacher-SBMHP contact regarding students, leaving both groups on their own to contact one another. Collaboration between the two groups was not actively discouraged, but it was not facilitated either. Further, neither school administrators, SBMHPs nor teachers appeared to attempt to clarify how different teacher responsibilities might 
change the way in which SBMHPs and teachers worked with shared students, resulting in confusion among teachers about where their responsibilities began and ended. Finally, just over half of the SBMHPs we interviewed, as contractual employees, were paid on a billable hours basis, which privileged traditional, office-based therapy and discouraged SBMHP participation in faculty meetings or other faculty efforts to address student or schoolwide issues, effectively cutting SBMHPs off from the teachers of students they served. It comes as little surprise, then, that some teachers did not engage in an a more expansive mental health support role.

Given that schools changed little to support teachers' changed work responsibilities, it follows that teachers' work remained separate from SBMHPs' work. Teachers remained largely relegated to the status of SBMH referral-makers, even when they did report consultations with SBMHPs. Processes that structured SBMH referrals—-the most consistent point of connection between teachers and SBMHPs—were themselves rigidly bureaucratized. Referral processes did not include protocols for post-referral SBMHP follow-up or work with teachers, even though many teachers remained involved with students and their needs. Overall, consultation, collaboration and professional development work that brought SBMHPs and teachers togetherwork that both groups of professionals described with interest and enthusiasm—was difficult to arrange, short of both groups volunteering time after hours.

Difficulties around the confidentiality of student information highlight the ways in which teachers' and SBMHPs' work remained restricted to professional siloes. While teachers respected SBMHPs' ethical commitments to preserve students' privacy, they did not always understand these commitments relative to their students' well being. SBMHPs appeared to interpret confidentiality guidelines in divergent ways, which also suggests difficulties in adapting these guidelines to the interpersonally rich and complex school setting. Without clear guidelines 
for teachers and SBMHPs in the complicated areas of student disclosure, mandated reporting of abuse and neglect, and other student risk behaviors, both groups of professionals operated largely on their own with little collaboration at potentially crucial moments in their students' lives. Under such conditions, neither the schools, their teachers nor their SBMHPs stood in a position to do anything much differently than would have been done in larger, ostensibly less personalized schools with more traditional teacher roles.

This observation brings us to our third point: our findings' surprising generalizability. This study's limitations—its somewhat homogeneous sample (small, urban high schools), a relatively small sample size including a limited number of different types of SBMHPs and the predominance of practitioner-reported data—would ordinarily constrain our findings' generalizability and may indeed have skewed our results. Yet, while acknowledging these important limitations, we also note how King's, Los Robles' and Western's personnel replicated issues seen at larger schools—structural rigidity and the fragmentation of professionals' work into siloes that small schools advocates (e.g., Darling-Hammond, 1997) describe as antithetical to student engagement and learning — that ultimately constrained professionals' work. As such, we point out that whether the three schools' structures and procedures for mental health services were "right" or "wrong" is less relevant than is their poor fit with the informal mental health support responsibilities that these schools placed upon their teachers.

\section{Implications for practice, professional learning and research}

These informative but somewhat disappointing findings point towards ways in which teachers and SBMHPs might more productively, sustainably and consistently work together to address student mental health needs. Our data suggest that meaningful change can be made in the organization of school-based mental health practice, learning opportunities for teachers and 
SBMHPs, and the development of interventions that intentionally involve teachers. Regarding school-based practice, SBMHPs and educators must develop school structures for mental health services that reflect, rather than constrain, schools' goals for student wellness. Structures suggested by our data include clearer expectations about SBMHPs' and teachers' respective roles related to student support, opportunities during the school day for teachers and SBMHPs to consult with one another about shared students (such as meetings built into both groups of professionals' schedules) and clear, consistent referral procedures that include protocols for what happens after teachers refer students to SBMHPs. Given schools' capacity to resist structural and cultural change (Mawhinney \& Smrekar, 1996; Tyack \& Cuban, 1995), atop SBMHPs' tendency to not focus on school leadership and school change issues (Kelly et al., 2010b), this is daunting work. Without it, though, we see no reason not to expect further underuse of valuable school resources, including school-based mental health services and teachers' time and energy.

Learning opportunities for teachers and SBMHPs can do much to ready these professionals for these challenges, as well as to more effectively combine their skills and resources in students' interest. Our findings add urgency to the work of scholars concerned with the development of teacher mental health competencies (Burke \& Paternite, 2007; Weston et al., 2008). Many teachers in this study were immersed in their students' mental health issues, ready or not. While calls for teacher training in mental health issues often focus on preservice education (e.g., Koller \& Bertel, 2006), we feel that it is also important to consider how SBMHPs can further incorporate teacher consultation and professional development roles into their practice, so that they can contribute to teacher learning related to student support needs. SBMHP training and practice tend towards clinical and diagnostic concerns (Berzin \& O'Connor, 2010), even though practitioners express interest in activities such as consultation (Brown et al., 
2006; Kelly et al., 2010b), and extant literature provides empirically-based guidance in this area (e.g., Atkins et al., 2006; Crothers, Hughes \& Morine, 2008). With additional learning experiences to prepare them for school-based consultation, SBMHPs might stand in a better position to help teachers extend and enhance their ability to recognize and respond to student psychosocial issues. Such activities also require SBMHP latitude to perform work activities other than individual counseling. School administrators and SBMHPs must share the responsibility for carving out space for this important work as they define priorities for SBMHP services. Interdisciplinary initiatives (see Anderson \& Bronstein, 2012), where teachers and SBMHPs learn together about consultation and collaboration, promises another route towards SBMH practice that reinforces teachers' unique, critical contributions to student wellness.

We also see here a clear opportunity for strong preventative programs that guide teachers' work with student mental health. None of the three schools used specific curriculum or interventions to treat or prevent student mental health problems. Evidence that SBMHPs and teachers intervened with students with little direct attention paid to existing evidence-based practices leads us to call for more inquiry into what actually drives the selection of mental health interventions in school settings. More research is needed drawing on the ideas of implementation science to better identify leverage points for implementing evidence-informed school mental health interventions where those interventions are sustainable and teacher-SBMHP collaboration is enhanced and deepened (see Cook \& Odom, 2013 and Proctor et al., 2009 for more details on implementation science). Further, an expanded research base for evidence-based SBMHP-teacher consultation could help teachers to better use SBMHP expertise in order to enhance their day-to-day classroom work. A more deliberate focus on developing a knowledge base about school mental health implementation science and evidence-informed SBMHP-teacher 
consultation models will help to improve schools' ability to address student needs at all three tiers and to improve the delivery of evidence-based classroom interventions.

\section{Conclusion}

This study's findings suggest that teachers represent an as-yet underused resource for promoting student mental health in an era when student needs are not only present but increasing. In order for schools to use this resource well and responsibly, however, adaptations of the school structures that underpin student mental health services, and of SBMHP and teacher practice, are necessary. Without those adaptations, teachers are likely to avoid the work, or, perhaps worse, do it poorly with a negative impact on students and their families. With those adaptations, however, schools stand to see a grounded expansion of the supports they could offer to students. 


\section{Appendix A: Sample Questions from Semi-Structured Interviews \\ Teacher interview questions.}

1. Are you expected to provide mental health support to your students? What are you supposed to do? How have you learned about these expectations?

2. What resources, if any, help you to meet these expectations? Does anything get in the way?

3. Could you tell me about the last time you provided mental health support to a student of yours? Tell me about the student and what you did. How do you think it turned out?

4. Do you collaborate with your school's SBMHP when students need mental health support? Could you tell me about the last time this happened?

5. With this experience you just described, what was your collaboration like? Were there times where your roles overlapped? Collided? Did anything get left undone? How did you feel about the parts of the work that were your responsibility? How typical was this experience?

6. Are there aspects of mental health support that you think are simply not your job? Is there any kind of mental health support that you have decided not to provide? What led you to that decision?

\section{SBHP interview questions.}

1. How would you describe the mission of the school? Do your services relate to it? What would you say is the purpose of mental health services at this school?

2. Tell me about how you do your job day-to-day. What is your approach to working with students? Does this differ at all from school staff's expectations of how you do your work?

3. How would you describe the teacher role relative to the mental health support of students at this school? How do teachers respond to these expectations?

4. How do students come to work with you? (Probe for teacher involvement in referral process)

5. Could you tell me how you collaborate with teachers once a student is engaged in services with you?

6. How would you compare your role here to a teacher's role? Advisor's role? 
Figures and Tables

Table 1.

Key Characteristics of Participating Schools, Teachers and School-Based Mental Health Professionals

\begin{tabular}{|c|c|c|c|}
\hline & King & Los Robles & Western \\
\hline Student enrollment & 358 & 295 & 345 \\
\hline $\begin{array}{l}\text { Proportion of students } \\
\text { eligible for free or reduced- } \\
\text { price lunch }\end{array}$ & $69 \%$ & $82 \%$ & $40 \%$ \\
\hline $\begin{array}{l}\text { Proportion of students of } \\
\text { color }\end{array}$ & $97 \%$ & $99 \%$ & $91 \%$ \\
\hline $\begin{array}{l}\text { Total number of teacher } \\
\text { participants }\end{array}$ & 15 & $20^{\mathrm{a}}$ & 11 \\
\hline Advisory program foci & $\begin{array}{l}\text { Academic skill } \\
\text { building college } \\
\text { awareness and } \\
\text { application }\end{array}$ & $\begin{array}{l}\text { Individual student } \\
\text { guidance, work } \\
\text { completion, college } \\
\text { awareness and } \\
\text { application }\end{array}$ & $\begin{array}{l}\text { Individual student } \\
\text { guidance, work } \\
\text { completion, college } \\
\text { awareness and } \\
\text { application, } \\
\text { community- } \\
\text { building }\end{array}$ \\
\hline $\begin{array}{l}\text { Advisory class minutes per } \\
\text { week }\end{array}$ & 80 & 245 & $\begin{array}{l}160\left(9 \text { th }-10^{\text {th }}\right. \\
\text { grades }) \\
190(11 \text { th }-12 \text { th } \\
\text { grades })\end{array}$ \\
\hline $\begin{array}{l}\text { School-based mental health } \\
\text { professional (SBMHP) } \\
\text { services provided }\end{array}$ & $\begin{array}{l}\text { Onsite health and } \\
\text { mental health clinic } \\
\text { (multiple SBMHPs, } \\
\text { clinic open } 30 \text { hours } \\
\text { per week serving } 3 \\
\text { co-located schools); } \\
\text { School counselor } \\
\text { (full-time) }\end{array}$ & $\begin{array}{l}\text { Two mental health } \\
\text { practitioners (part- } \\
\text { time); Medical van } \\
\text { with social work } \\
\text { services ( } 2 \text { days per } \\
\text { month) }\end{array}$ & $\begin{array}{l}\text { One mental health } \\
\text { practitioner (part- } \\
\text { time) }\end{array}$ \\
\hline $\begin{array}{l}\text { Participating SBMHPs and } \\
\text { areas of certification }\end{array}$ & $\begin{array}{l}\text { - Dr. Beltrán, } \\
\text { Psychologist } \\
\text { - Ms. Ortiz, School } \\
\text { Counselor }\end{array}$ & $\begin{array}{l}\text { - Ms. Garza, Social } \\
\text { Worker } \\
\text { - Ms. George, } \\
\text { Social Worker } \\
\text { - Dr. Moisés, } \\
\text { Psychologist } \\
\text { - Ms. Peterson, } \\
\text { Social Worker } \\
\end{array}$ & $\begin{array}{l}\text { - Ms. Cruz, } \\
\text { Marriage and } \\
\text { Family Therapist } \\
\text { (graduate intern } \\
\text { under offsite } \\
\text { supervision) }\end{array}$ \\
\hline
\end{tabular}

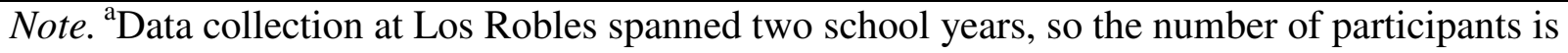
slightly higher due to staff turnover and replacement. 
Table 2.

Categories of analytic codes applied to interview transcripts and examples of codes

Code category

Role definition (by

professionals and by school)
Examples of codes from each category

- School administrator definition of teacher's informal mental health support role

- SBMHP understanding of own role related to teachers' work

- Distinction of teachers' and SBMHPs' responsibilities

Structures and resources related to teachers' mental health support responsibilities

\begin{tabular}{ll}
\hline Teacher responses & - Teacher comfort with informal mental health support \\
& responsibilities \\
& - Teacher detachment from advisor role or advisees \\
& - Teacher emotional distress \\
\hline School-based mental health & - Consultation between SBMHP and teacher \\
professional (SBMHP) & - Teacher referral of student to SBMHP \\
involvement with teacher(s) & - Organizational constraints upon collaboration \\
\hline
\end{tabular}

Table 3.

Types of Teacher Encounter with Student Mental Health Issues

\begin{tabular}{lll}
\hline Type of Teacher Encounter & Examples \\
\hline $\begin{array}{l}\text { Addressing student behavior as } \\
\text { part of the advisor role }\end{array}$ & $\bullet$ & Receiving students sent out of class for misbehavior \\
\hline $\begin{array}{l}\text { Student disclosure of mental } \\
\text { health-related issues }\end{array}$ & - Implementing student behavior plans \\
& - $\begin{array}{l}\text { Disclosure of immediate safety concerns } \\
\text { grief, gang involvement, drug use, family illness) }\end{array}$ \\
\hline $\begin{array}{l}\text { Teacher coordination of support } \\
\text { and service referrals }\end{array}$ & - Contact with out-of-school service providers \\
\hline
\end{tabular}


Table 4.

Types of teacher role definition related to student mental health support responsibilities Role Teachers choosing role Examples of teacher actions definition type definition type, by school

\begin{tabular}{|c|c|c|}
\hline \multirow[t]{3}{*}{ Diffuse } & King: 5 & \multirow{3}{*}{$\begin{array}{l}\text { - Discussion of mental health issues with students } \\
\text { - Intervention when mental health issues arise } \\
\text { - Referral of students to school-based mental } \\
\text { health professionals, retaining a high degree of } \\
\text { involvement with students post-referral } \\
\text { - Mental health service coordination }\end{array}$} \\
\hline & Los Robles: 12 & \\
\hline & Western: 5 & \\
\hline \multirow[t]{3}{*}{ Narrow } & King: 9 & \multirow{3}{*}{$\begin{array}{l}\text { Engagement with students solely around } \\
\text { academic issues } \\
\text { - Referral of students to SBMHPs for all social- } \\
\text { emotional support }\end{array}$} \\
\hline & Los Robles: 9 & \\
\hline & Western: 11 & \\
\hline
\end{tabular}

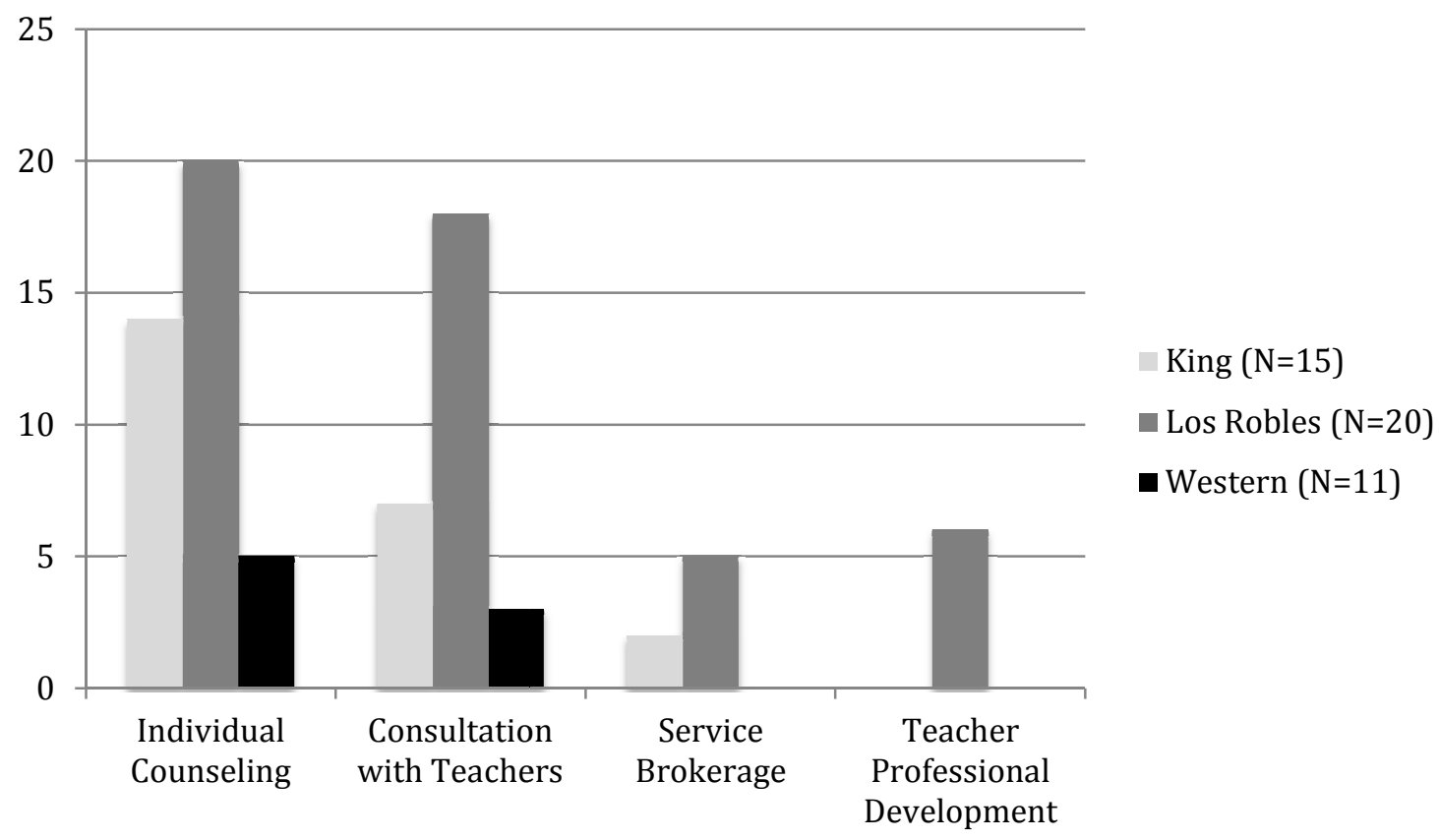

Figure 1. Number of teachers reporting different types of services provided by school-based mental health professionals, sorted by school. 


\section{References}

Albers, C. A., \& Kratchowill, T. R. (2006). Teacher and principal consultations: Best practices. In C. Franklin, M. B. Harris \& P. Allen-Meares (Eds.), The school services sourcebook: A guide for school-based professionals (pp. 971-976). New York, NY: Oxford Press.

American School Counselor Association. (2010). Ethical standards for school counselors.

Retrieved December 10, 2012, from

http://www.schoolcounselor.org/files/EthicalStandards2010.pdf

Anderson, E. M., \& Bronstein, L. R. (2012). Examining interdisciplinary collaboration within an expanded school mental health framework: a community-university initiative. Advances in School Mental Health Promotion,5(1), 23-37.

Atkins, M. S., Frazier, S. L., Birman, D., Adil, J. A., Jackson, M., Graczyk, P. A., et al. (2006). School-based mental health services for children living in high poverty urban communities. Administration and Policy in Mental Health and Mental Health Services Research, 33(2), 146-159.

Atkins, M. S., Hoagwood, K. E., Kutash, K., \& Seidman, E. (2010). Toward the integration of education and mental health in schools. Administration and Policy in Mental Health and Mental Health Services Research, 37(1), 40-47.

Berzin, S. C., \& O'Connor, S. (2010). Educating Today's School Social Workers: Are School Social Work Courses Responding to the Changing Context? Children \& Schools, 32(4), 237-249.

Borko, H. (2004). Professional development and teacher learning: Mapping the terrain. Educational Researcher, 33(8), 3-15.

Brown, M. B., Holcombe, D. C., Bolen, L. M., \& Thomson, W. S. (2006). Role function and job 
satisfaction of school psychologists practicing in an expanded role model. Psychological reports, 98(2), 486 .

Burke, R. W., \& Paternite, C. E. (2007). Teacher engagement in expanded school mental health. In S. Evans, Z. Serpell \& M. D. Weist (Eds.), Advances in school-based mental health (Vol. 2, pp. 21.21-21.15). Kingston, NJ: Civic Research Institute.

Burnham, J. J., \& Jackson, C. M. (2000). School Counselor Roles: Discrepancies between Actual Practice and Existing Models. Professional School Counseling, 4(1), 41-49.

Chanmugam, A. (2009). A Qualitative Study of School Social Workers' Clinical and Professional Relationships when Reporting Child Maltreatment. Children \& Schools, 31(3), 145-161.

Cook, B. G., \& Odom, S. L. (2013). Evidence-Based Practices and Implementation Science in Special Education. Exceptional Children, 79(2), 135-144.

Croninger, R. G., \& Lee, V. E. (2001). Social capital and dropping out of high school: Benefits to at-risk students of teachers' support and guidance. Teachers College Record, 103(4), 548-581.

Crothers, L. M., Hughes, T. L., \& Morine, K. A. (2008). Theory and cases in school-based consultation: A resource for school psychologists, school counselors, special educators and other mental health professionals. New York, NY: Routledge.

Darling-Hammond, L. (1997). The right to learn: A blueprint for creating schools that work. San Francisco: Jossey-Bass.

Dryfoos, J. G., Quinn, J., \& Barkin, C. (Eds.). (2005). Community schools in action: Lessons from a decade of practice. New York, NY: Oxford University Press. 
Emerson, R.M., Fretz, R.I., \& Shaw, L.L. (1995). Writing Ethnographic Fieldnotes. Chicago, IL: The University of Chicago Press.

Evans, S. W., Sapia, J. L., Lowie, J. A., \& Glomb, N. K. (2002). Practical issues in school mental health: Referral procedures, negotiating special education, and confidentiality. In H. S. Ghuman, M. D. Weist \& R. M. Sarles (Eds.), Providing mental health services to youth where they are: School- and community-based approaches (pp. 75-93). New York: Brunner-Routledge.

Farrell, P. (2010). School psychology: Learning lessons from history and moving forward. School Psychology International, 31(6), 581-598.

Franklin, C. G., Kim, J. S., Ryan, T. N., Kelly, M. S., \& Montgomery, K. L. (2012). Teacher involvement in school mental health interventions: A systematic review. Children and Youth Services Review.

Freedenthal, S., \& Breslin, L. (2010). High school teachers' experiences with suicidal students: A descriptive study. Journal of Loss and Trauma, 15(2), 83-92.

Frey, A. J., Lingo, A., \& Nelson, C. M. (2008). Positive behavior support: A call for leadership. Children \& Schools, 30(1), 5-14.

Galassi, J. P., Gulledge, S. A., \& Cox, N. D. (1998). Advisory: Definitions, descriptions, decisions, directions. Westerville, $\mathrm{OH}$ : National Middle School Association.

Jaycox, L. H., Langley, A. K., Stein, B. D., Wong, M., Sharma, P., Scott, M., \& Schonlau, M. (2009). Support for students exposed to trauma: A pilot study. School Mental Health, $1(2), 49-60$. 
Kelly, M. S., \& Lueck, C. (2011). Adopting a Data-Driven Public Health Framework in Schools: Results from a Multi-Disciplinary Survey on School-Based Mental Health Practice. Advances in School Mental Health Promotion,4(4), 5-12.

Kelly, M. S., Berzin, S. C., Frey, A., Alvarez, M., Shaffer, G., \& O’Brien, K. (2010a). The state of school social work: Findings from the national school social work survey. School Mental Health, 2(3), 132-141.

Kelly, M. S., Raines, J. C., Stone, S., \& Frey, A. (2010b). School Social Work: An EvidenceInformed Framework for Practice: An Evidence-Informed Framework for Practice. Oxford University Press, USA.

Kelly, M. S. (2008). The domains and demands of school social work practice: A guide to working effectively with students, families and schools. Oxford University Press, USA.

Koller, J. R., \& Bertel, J. M. (2006). Responding to today's mental health needs of children, families and schools: Revisiting the preservice training and preparation of school-based personnel. Education and Treatment of Children, 29(2), 197-217.

Kvale, S., \& Brinkmann, S. (2009). Interviews: Learning the craft of qualitative research interviewing (2nd ed.). Thousand Oaks, CA: Sage.

Langley, A. K., Nadeem, E., Kataoka, S. H., Stein, B. D., \& Jaycox, L. H. (2010). Evidencebased mental health programs in schools: Barriers and facilitators of successful implementation. School mental health, 2(3), 105-113.

Lewis, J., Ream, R., Bocian, K., Fast, L., Cardullo, R., \& Hammond, K. (2012). Con Cariño: Teacher caring, math self-efficacy and math achievement among Hispanic English learners. Teachers College Record, 114(7), 1-42. 
Lortie, D. C. (2002). Schoolteacher: A sociological study (2nd ed.). Chicago, IL: University of Chicago Press.

Mathews, J. (2009). Work hard. Be nice: How two inspired teachers created the most promising schools in America. Chapel Hill, NC: Algonquin Books.

Mawhinney, H. B., \& Smrekar, C. E. (1996). Negotiating the institutional constraints in school/community collaborations. Educational Policy, 10(4), 480-501.

McClure, L., Yonezawa, S., \& Jones, M. (2010). Can school structures improve teacher student relationships? The relationship between advisory programs, personalization and students' academic achievement. Education Policy Analysis Archives, 18(17), 1-21.

McNeely, C. A., \& Falci, C. (2004). School connectedness and the transition into and out of health-risk behavior among adolescents: A comparison of social belonging and teacher support. Journal of School Health, 74(7), 284-292.

Meehan, B.T., Hughes, J.N., \& Cavell, T.A. (2003). Teacher-Student Relationships as Compensatory Resources for Aggressive Children. Child Development, 74(4), 1145-1157.

Merriam, S. B. (2009). Qualitative research: A guide to design and implementation (Third ed.). San Francisco, CA: Jossey-Bass.

Meyers, A.B., Meyers, J., Graybill, E.C., Proctor, S.L., \& Huddleston, L (2012). Ecological Approaches to Organizational Consultation and Systems Change in Educational Settings. Journal of Educational and Psychological Consultation, 22(1-2), 106-124.

Miles, M. B., Huberman, A. M. \& Saldaña, J. (2013). Qualitative data analysis: An expanded sourcebook (3rd ed.). Thousand Oaks, CA: Sage Publications.

National Association of Social Workers. (2008). Code of Ethics. Washington, D.C.: Author. National Education Association. (1975). Code of ethics of the education profession. Retrieved 
March 11, 2013 from http://www.nea.org/home/30442.htm

Owens, J. S., Holdaway, A. S., Zoromski, A. K., Evans, S. W., Himawan, L. K., Girio-Herrera, E., \& Murphy, C. E. (2012). Incremental benefits of a daily report card intervention over time for youth with disruptive behavior. Behavior Therapy, 43(4), 848-861.

Phillippo, K.L. (2013). Advisory in Urban High Schools: A Study of Expanded Teacher Roles. New York, NY: Palgrave Macmillan.

Phillippo, K.L. (2010). Teachers providing social and emotional support: A study of complex role enactment in small high schools. Teachers College Record, 112(8), 2258-2293.

Proctor, E. K., Landsverk, J., Aarons, G., Chambers, D., Glisson, C., \& Mittman, B. (2009). Implementation research in mental health services: An emerging science with conceptual, methodological, and training challenges. Administration and Policy in Mental Health and Mental Health Services Research, 36(1), 24-34.

Raines, J. C. (2004). To tell or not to tell: Ethical issues regarding confidentiality. School Social Work Journal, 28(2), 61-78.

Reddy, R., Rhodes, J.E., \& Murhall, P. (2003). The influence of teacher support on student adjustment in the middle school years: A latent growth curve study. Development and psychopathology, 1, 119-138.

Reinke, W. M., Stormont, M., Herman, K. C., Puri, R., \& Goel, N. (2011). Supporting children's mental health in schools: Teacher perceptions of needs, roles, and barriers. School Psychology Quarterly, 26(1), 1.

Roorda, D. L., Koomen, H. M. Y., Spilt, J. L., \& Oort, F. J. (2011). The influence of affective teacher-student relationships on students' school engagement and achievement: A metaanalytic approach. Review of Educational Research, 81(4), 493-529. 
Sabatino, C.A. (2009). School social work consultation models and response to intervention: A perfect match. Children \& Schools, 31(4), 197-206.

Saldaña, J. (2013). The coding manual for qualitative researchers (2nd ed.). Thousand Oaks, CA: Sage

Schoolmentalhealth.org (2009). What is (expanded) school mental health? Retrieved from http://www.schoolmentalhealth.org/Resources/ESMH/DefESMH.html

Sizer, T. R. (1992). Horace's compromise: The dilemma of the American high school. Boston, MA: Houghton Mifflin.

Spindler, G., \& Spindler, L. (1987). Interpretive ethnography of education: At home and abroad. Hillsdale, NJ: Erlbaum Associates.

Streb, C.K. (2010). Exploratory case study. In A.J. Mills, G. Duprepos \& E. Wiebe (Eds.), Encyclopedia of case study research (pp. 373-375). Thousand Oaks, CA: Sage.

Strike, K. A. (2010). Small Schools and Strong Communities: A Third Way of School Reform. New York, NY: Teachers College Press.

Sugai, G., \& Horner, R. H. (2009). Responsiveness-to-intervention and school-wide positive behavior supports: Integration of multi-tiered system approaches. Exceptionality, 17(4), 223-237.

Taylor, S.J, \& Bogdan, R. (1998). Introduction to qualitative research methods (Third ed.). New York: John Wiley and Sons.

Tyack, D.B. (1974). The one best system: A history of American urban education. Cambridge, MA: Harvard University Press.

Tyack, D., \& Cuban, L. (1995). Tinkering toward utopia: A century of public school reform. Cambridge, MA: Harvard University Press. 
Weist, M. D., Lowie, J. A., Flaherty, L. T., \& Pruitt, D. (2001). Collaboration among the education, mental health, and public health systems to promote youth mental health. Psychiatric Services, 52(10), 1348-1351.

Weist, M. D. \& Murray, M. (2007). Advancing school mental health promotion globally. Advances in School Mental Health Promotion, 1(sup1), 2-12.

Weston, K. J., Anderson-Butcher, D., \& Burke, R. W. (2008). Developing a comprehensive curriculum framework for teacher preparation in expanded school mental health. Advances in School Mental Health Promotion, 2(4), 25-41.

Yin, R. K. (2009). Case study research: Design and methods (4th ed.). Thousand Oaks, CA: Sage. 